Savill, Nicola ORCID:

https://orcid.org/0000-0002-6854-0658, Lindell, Annukka, Booth, Alison, West, Gemma and Thierry, Guillaume (2010) Literate humans sound out words during silent reading. NeuroReport, 22 (3). pp. 116-120.

Downloaded from: http://ray.yorksj.ac.uk/id/eprint/3276/

The version presented here may differ from the published version or version of record. If you intend to cite from the work you are advised to consult the publisher's version:

Research at York St John (RaY) is an institutional repository. It supports the principles of open access by making the research outputs of the University available in digital form. Copyright of the items stored in RaY reside with the authors and/or other copyright owners. Users may access full text items free of charge, and may download a copy for private study or non-commercial research. For further reuse terms, see licence terms governing individual outputs. Institutional Repository Policy Statement

\title{
RaY
}

Research at the University of York St John

For more information please contact RaY at ray@yorksj.ac.uk 


\section{Literate humans sound out words during silent reading}

Nicola Savill ${ }^{\mathbf{a}}$, Annukka Lindell ${ }^{\mathbf{b}}$, Alison Booth ${ }^{\mathbf{a}}$, Gemma West ${ }^{\mathbf{a}}$, and Guillaume Thierry $^{\text {a }}$

${ }^{a}$ School of Psychology, Bangor University, Gwynedd, LL57 2AS, UK

${ }^{\mathrm{b}}$ School of Psychological Science, La Trobe University, Australia

Running head: PHONOLOGICAL ACTIVATION IN READING

Correspondence:

Nicola Savill

School of Psychology

Bangor University

Bangor

Gwynedd

LL57 2AS

Tel: $+44(0) 1248388584$

Fax: +44(0)1248382599

Email: n.j.savill@bangor.ac.uk

Funding sources: This work is supported by the ESRC, BBSRC and British Foundation for Women Graduates.

Total characters 23308

Body text characters 16824 


\begin{abstract}
Whether humans spontaneously sound out words in their mind during silent reading is a matter of debate. Some models of reading postulate that skilled readers access meaning directly from print but others involve print-to-sound transcoding mechanisms. Here we provide evidence that silent reading activates the sound form of words prior to meaning access by comparing event-related potentials induced by highly expected words and their homophones. We found that expected words and words that sound the same but have a different orthography (homophones and pseudohomophones) reduce scalp activity to the same extent within $300 \mathrm{~ms}$ of presentation compared to unexpected words. This demonstrates that phonological access during silent reading, which is critical for literacy acquisition, remains active into adulthood.
\end{abstract}

Keywords: Event-related potential, reading, phonology, semantic access, N2, N400, homophone, pseudohomophone. 


\section{Introduction}

Studies that have tested phonological effects during single word reading have shown brain activity modulations as early as $100 \mathrm{~ms}$ [1-4], suggesting a fundamental role for phonology. However, whether phonological information is spontaneously retrieved when accessing semantic information in reading is open to debate [5-7]. To test whether the phonological form of written words is activated during silent reading, we measured the N2 and N400 peaks of event-related potentials (ERPs), which reflect the degree of phonological and semantic mismatch, respectively, between a word and the context in which it appears [8-11]. For example, in the spoken sentence 'an eagle is a bird of flare', the word 'flare' would elicit a larger N2 and N400 compared to 'prey' since it is neither phonologically nor semantically expected in the sentence context [10]. Since the $\mathrm{N} 2$ is sensitive to phonological expectation about words, significant reduction in its amplitude for both an expected word and its homophone relative to an unexpected word in visually presented sentences would provide strong evidence that the sound form of words is retrieved during silent reading.

Most of the existing ERP studies investigating this question have not found convincing evidence for phonological involvement in accessing the meaning of written words. In the case of single word reading, one ERP study [11] testing phonological access in a semantic categorisation task found no N400 differences between homophones of category exemplars (e.g. "meet" for the category of food) as compared to orthographic controls (e.g. "melt"). In the context of behavioural data showing higher error rates in the homophone condition (homophones were more likely to be accepted as correct category members than orthographic control items), the conclusion was that the 
phonological effects occur after semantic integration indexed by the N400. However, the possibility was raised that the increased processing demands of reading sentences for meaning might show greater phonological involvement [11].

Previous sentence reading studies have examined phonological activation by replacing semantically primed finals words with unexpected words sharing initial phonemes [12], homophones [13-14] or pseudohomophones (pseudowords homophonic to a real word) [15]. Some have found evidence for phonological effects in semantic integration indexed by the N400 [14-15], while others have not [12-13]. Furthermore, these studies have found only weak earlier phonological reductions in the $\mathrm{N} 2$ range and moreover concluded that $\mathrm{N} 2$ modulations in reading are primarily related to orthographic violation [15]. However, these previous results have only provided limited insight regarding spontaneous phonological activation in silent reading, because they have either (a) not used a controlled task (e.g., no behavioural monitoring in the case of Refs. 12, 14, 15), (b) not used sentences with high cloze probability (Ref. 13), and/or (c) not controlled cloze probability across experimental conditions (i.e., they used difference sentence contexts across conditions in 12,15$)$. Cloze probability is the numerical probability of a given word to be selected to complete a given sentence context (e.g., the cloze probability of 'prey' in the sentence starting 'An eagle is a bird of..." is close to 1).

Indirect evidence for phonological activation in sentence reading comes from a study on misspellings [16], in which expectancy was manipulated by presenting low- and highcloze probability sentences containing a congruent word or its pseudohomophone. In the N2 time range (N270), differences between words and pseudohomophones were found in the context of low-cloze sentences but not that of high-cloze sentences. 
Although the aim of the study was to investigate the processing of misspellings, this result is compatible with phonological mediation in silent reading, since pseudohomophones - when highly constrained by sentence context - are phonologically expected. In the same study, words and pseudohomophones also reduced ERP amplitudes in the N400 range when presented in a high-cloze probability sentence [16], suggesting that phonological activation during silent reading may extend into the window of semantic integration $[15,17]$.

Here, we tested whether participants reading silently for meaning would show phonological processing of stimuli that are orthographically and semantically inappropriate but phonologically expected, when reading highly constrained sentences. Our main question was whether homophones and pseudohomophones presented at the end of a highly constrained sentence would reduce the amplitude of the $\mathrm{N} 2$ peak relative to totally unexpected endings $[10,18]$. Our predictions were as follows: If retrieval of the phonological form of written words is spontaneous during silent reading, we should observe a reduced N2 peak in all conditions except for totally unexpected completions. In addition, retrieval of the phonological form of a homophone or pseudohomophone was expected to activate the semantic representation of the best completion and thus similarly reduce the subsequent $\mathrm{N} 400[9,17]$.

\section{Method}

\section{Participants}

Fifteen undergraduate students participated as partial fulfilment of a course requirement (11 females; Mean age 19.3 years, range 18-24 years) in our study approved by Bangor 
University's Ethics Committee. All had normal, or corrected-to-normal, vision and were native speakers of English.

\section{Stimuli}

To ensure that the 'best completion' stimuli were highly predictable from the preceding sentence context, a separate group of 37 participants completed a series of sentences that were missing the final word with their most likely ending (e.g., "Rob looked at his watch to check the..." elicited the response "time"). Sentences were included on the basis of their percentage predictability: Each had a minimum of 0.80 Cloze Probability, with an average Cloze Probability of 0.84 for the final 'best completion' stimuli.

There were four experimental conditions: best completion (BC; e.g., "time"); homophone of the best completion (HO; e.g., "thyme"); pseudohomophone of the best completion (PH; orthographically legal pseudowords homophonic to the best completion; e.g., "tyme"); and unrelated (UN; words unrelated to the sentence context; e.g., "skull"). BC, HO and UN word lists were matched for lexical frequency (Mean $\log =1.13 \pm 0.7), \quad$ concreteness $\quad($ Mean $=465 \pm 99), \quad$ length $\quad($ Mean $=4.6 \pm 1) \quad$ and grammatical class [19]. Sentences ranged from 5 to 12 words in length.

Of the four stimulus conditions, three provided endings incongruent with the sentence whilst only one (best completion) provided a congruent completion. To avoid spurious P300 effects prompted by unbalanced proportion between best completion and other experiment conditions, we created a filler best completion condition [20]. These fillers comprised sentences with congruent endings but had no corresponding homophone or pseudohomophone equivalent and were not analyzed. The complete stimulus set 
comprised a total of 240 words: 40 words in each of the four critical experimental conditions (BC, $\mathrm{HO}, \mathrm{PH}, \mathrm{UN})$, and 80 words in the filler best completion condition.

\section{Procedure}

Participants were comfortably seated in a darkened, acoustically and electrically shielded room. A high-resolution CRT monitor was centred approximately $100 \mathrm{~cm}$ from participants' eyes. They were instructed to fixate the centre of the screen and to minimize eye and body movement throughout the ERP recording. Participants were asked to indicate whether the final word was congruent or incongruent with the preceding sentence by pressing either the ' $F$ ' or ' $J$ ' keys (with the left and right index fingers respectively). Response side was alternated between blocks and counterbalanced across participants. The 240 stimuli were divided into 4 blocks of 60 trials. In each trial, the sentence was presented one word at a time for $200 \mathrm{~ms}$ with an inter-stimulus-interval of $300 \mathrm{~ms}$. Following presentation of the final word participants had 2 seconds to respond. Each word subtended a maximum visual angle of $4^{\circ} \times 0.8^{\circ}$. Individual reaction times (RTs) for correct responses were averaged as a function of experimental condition. Incorrect responses and non-responses were coded as errors.

\section{EEG recording and analysis}

Electrophysiological (EEG) data were recorded (1 kHz sampling rate; SynAmps2 amplifiers; Neuroscan Inc., El Paso, USA) from $32 \mathrm{Ag} / \mathrm{AgCl}$ electrodes in reference to $\mathrm{Cz}$ (impedance $<11 \mathrm{k} \Omega$ ). Electrodes were placed in accordance with the International 10-20 System at frontal (Fp1, Fp2, Fz, F3, F4, F7, F8), central (C3, C4), temporal (T7, T8), parietal (Pz, P3, P4, P7, P8) and occipital (O1, O2) sites, with additional electrodes in anterior frontal (AFz), fronto-temporal (FT9, FT10), fronto-central (FC1, FC2, FC5, 
FC6), central-parietal (CP1, CP2, CP5, CP6) and parieto-occipital (PO9, PO10) locations. Electrodes above and below the left eye monitored eye blink activity. EEG signal was filtered online between 0.1 and $100 \mathrm{~Hz}$ and re-filtered offline using a zerophase shift using a $20 \mathrm{~Hz}$ cut-off low pass. Neuroscan software (Scan 4.2) was used to mathematically correct eye blinks. Epochs ranged from -100 to $1000 \mathrm{~ms}$ after final word onset. Baseline correction was performed in reference to $100 \mathrm{~ms}$ pre-stimulus activity. At least 30 correct response epochs were obtained for each experimental condition (acceptance of best completions; rejections for the remainder) for each participant. Individual averages, which were digitally re-referenced to the global average reference, were averaged to produce the grand-average ERPs. Mean amplitudes were measured at electrodes FC1, FC2 and Fz between 250 and $350 \mathrm{~ms}$ for the N2 and CP1, CP2 and Pz between 350 and $500 \mathrm{~ms}$ for the N400. For both peaks, individual mean amplitudes and peak latencies for each condition were subjected to repeated measures ANOVAs with within subject factors of condition (BC, $\mathrm{HO}, \mathrm{PH}, \mathrm{UN}$ ) and electrode (3 electrodes).

\section{Results}

\section{Behavioural Data}

Repeated measures ANOVA indicated that experimental conditions significantly affected reaction times $[\mathrm{F}(3,14)=6.57, P<.05]$, with $\mathrm{PH}$ stimuli eliciting faster responses compared to other conditions [All $P s<.05$; Fig. 1]. Error rates also differed between experimental conditions $[\mathrm{F}(3,14)=12.25, P<.01$; see Fig. 1]. Both BC and PH conditions yielded lower error rates than the $\mathrm{HO}$ and UN conditions [all $P s<.05$ ]. Differences between $\mathrm{BC}$ and $\mathrm{PH}$ on the one hand, and between $\mathrm{HO}$ and $\mathrm{UN}$ on the other hand were non-significant [all $P s>.1]$. 


\section{Please insert Figure 1 about here}

\section{Electrophysiological Data}

P1 and N1 components elicited by words in final position peaked at 115 and $223 \mathrm{~ms}$, respectively, and were unaffected by experimental conditions either in amplitude or latency. The N2 peaked at $317 \mathrm{~ms}$ over the frontal area, and was maximal at Fz. The N400 was a broad negative wave maximal at centroparietal electrodes.

N2 peak latency was insensitive to experimental conditions $[P>.1]$, but its mean amplitude was affected by experimental condition $[\mathrm{F}(3,14)=7.81, P<.05$; Fig. 2]. Post hoc t-tests indicated that the $\mathrm{N} 2$ elicited by the UN condition was larger compared to all other conditions: [BC-UN: $t(14)=2.03, P<.05 ;$ HO-UN: $t(14)=2.82, P<.05$; PH-UN $t(14)=2.70, P<.05]$, while differences between $\mathrm{BC}, \mathrm{HO}$ and $\mathrm{PH}$ considered in pairs were non-significant.

\section{Please insert Figure 2 about here}

N400 amplitude was modulated by experimental condition, $[\mathrm{F}(3,14)=21.26, P<.05]$. Post hoc comparisons showed that the N400 component was significantly more negative for the UN condition than in the other three experimental conditions [BC-UN $t(14)=6.24, P<.05 ; \mathrm{HO}-\mathrm{UN} t(14)=5.67, P<.05 ; \mathrm{PH}-\mathrm{UN} t(14)=8.57, P<.05]$. The BC, $\mathrm{HO}$ and $\mathrm{PH}$ conditions showed a substantially reduced wave and there were no differences between them $[P>.05$; Fig. 2]. Due to the absence of peak in the N400 range in $\mathrm{BC}, \mathrm{HO}$ and $\mathrm{PH}$, no latency analysis was performed in the $\mathrm{N} 400$ range.

\section{Discussion}


This study investigated online phonological activation during silent reading and its implication for semantic integration mechanisms. We found that unexpected sentence completions prompted an $\mathrm{N} 2$ effect. As predicted, the N2 amplitude was significantly reduced for phonologically congruent completions (whether orthographically expected or not) as compared to unexpected completions. Furthermore, a large amplitude N400 indexing violation of semantic expectancy was found only in the unexpected completion condition whereas the N400 elicited by phonologically congruent sentence completions (best completion, homophone, pseudohomophone) was substantially reduced and nondiscriminative. Thus, in a context where orthographic and semantic expectation was maximal and despite the fact that phonological retrieval was detrimental to the task at hand -since homophone and pseudohomophone had to be judged as incorrect completions- participants systematically accessed the sound form of the printed word within 300 ms. Furthermore, the N400 reduction observed for all homophone conditions indicates that phonological activation of the best completion sound form triggered semantic access.

From a behavioural point of view, we found that orthography discriminated between the expected and homophonic completions. Error rates were higher in the homophone condition than in other conditions. Moreover, participants were faster and more accurate in rejecting pseudohomophones than any other stimulus type. Since both homophone and pseudohomophone conditions shared phonological representations with best completions, orthography is the only basis upon which correct rejections could be made. Therefore, different performance in the two homophonic conditions was probably due to relative differences in orthographic familiarity [21]: Pseudohomophones were 
orthographically unfamiliar, making it easier to reject them than homophones, which were real words.

It may be argued that amplitude reductions observed in the N2 and N400 ranges could have been prompted by orthographic rather than phonological similarity between BC, $\mathrm{HO}$ and $\mathrm{PH}$ conditions [22]. However, orthographic similarity is unlikely to account for the degree of attenuation observed here because (i) Since homophones and pseudohomophones were correctly rejected and best completion words accepted, the N2 reduction found in former conditions should not have been as pronounced as that seen in the best completion condition if this decision had been made based on orthography alone; (ii) Non-homophonic pseudowords usually elicit larger N400 amplitudes than pseudohomophones, even when they are matched for orthographic similarity with word targets [23] (orthographically-driven effects have even been found as early as $150 \mathrm{~ms}$ [3]); and (iii) Unexpected orthographic neighbours of highly expected words have been shown to elicit significantly larger N400 waves than expected sentence completions [24]. As in the present study homophones and pseudohomophones were less than $60 \%$ orthographically similar to best completion words (HO mean similarity .59 based on normalised edit distance, NED [25], SD .18; PH NED .55, SD .20) one would have expected larger N400 amplitudes if the effect had been driven by orthographic similarity.

Overall our results appear inconsistent with previous studies showing larger N2 peaks to homophones [13-14] and pseudohomophones [15] as compared to semantically congruent words. However, in our study sentence cloze probability was manipulated so as to make phonological priming effects particularly strong (see also ref. 16) which we 
assume lead to automatic phonological activation overriding effects of orthographic expectation until after the window of semantic integration. We speculate that the previous conflicting findings regarding phonological integration indexed by the N2 may be accounted for by the absence of strong phonological expectations in the reader [1215]. In this situation, phonological activation may be at a sub-threshold level vulnerable to interference from mismatch responses elicited by dissonant orthographic forms and would result in the observed increased N2 modulations [12, 13, 15], indexing early conflicts between orthographic and phonological processing $[15,18]$. Such a conflict would presumably reduce phonological integration and subsequent semantic access triggered by the stimulus [e.g., Ref. 11].

\section{Conclusion}

Despite being correctly rejected as inappropriate sentence completions, homophones and pseudohomophones appear to elicit N2s and N400s of similar amplitude to those elicited by predictable words. This result provides new evidence that whilst final meaning selection may be constrained by orthography, phonological information is accessed and mediates semantic access during sentence reading.

\section{Acknowledgements}

The authors wish to thank Mark Roberts for assistance. The authors declare that there are no conflicts of interest.

\section{References}

1. Ashby J, Sanders LD, Kingston J. Skilled readers begin processing phonological features by 80 msec: Evidence from ERPs. Biol Psychol 2009; 80: 84-94. 
2. Ashby J. Phonology is fundamental in skilled reading: Evidence from ERPs. Psychon Bull Rev 2010; 17: 95-100.

3. Braun M, Hutzler F, Ziegler JC, Dambacher M, Jacobs AM. Pseudohomophone effects provide evidence of early lexico-phonological processing in visual word recognition. Hum Brain Mapp 2009; 30: 1977-1989.

4. Wheat KL, Cornelissen PL, Frost SJ, Hansen PC. During Visual Word Recognition, Phonology Is Accessed within 100 ms and May Be Mediated by a Speech Production Code: Evidence from Magnetoencephalography. J Neurosci 2010; 30: 5229-5233.

5. Taft M, van Graan G. Lack of phonological mediation in a semantic categorization task. J Mem Lang 1998; 38: 203-224.

6. Coltheart M, Curtis B, Atkins P, Haller M. Models of reading aloud: Dual-route and parallel-distributed-processing approaches. Psychol Rev 1993; 100: 589608.

7. Lukatela G,Turvey MT. Visual lexical access is initially phonological: 2. Evidence from phonological priming by homophones and pseudohomophones. $J$ Exp Psychol Gen 1994; 123: 331-353.

8. Näätänen R. The role of attention in auditory information processing as revealed by event-related potentials and other brain measures of cognitive function. Behav Brain Sci 1990; 13: 201-288.

9. Kutas M, Hillyard SA. Reading senseless sentences: brain potentials reflect semantic incongruity. Science 1980; 207: 203-205. 
10. Connolly JF, Phillips NA. Event-related potential components reflect phonological and semantic processing of the terminal word of spoken sentences. J Cogn Neurosci 1994; 6: 256-266.

11. Ziegler JC, Benraiss A, Besson M. From print to meaning: An electrophysiological investigation of the role of phonology in accessing word meaning. Psychophysiology 1999; 36: 775-785.

12. Connolly JF, Phillips NA, Forbes KAK. The effects of phonological and semantic features of sentence-ending words on visual event-related brain potentials. Electroencephalogr Clin Neurophysiol 1995; 95: 276-287.

13. Niznikiewicz M, Squires NK. Phonological processing and the role of strategy in silent reading: behavioral and electrophysiological evidence. Brain Lang 1996; 52: 342-363.

14. Ren, G-Q, Lui Y, Han Y-C. Phonological activation in Chinese reading: An event-related potential study using low-resolution electromagnetic tomography. Neuroscience 2009; 164: 1623-1631.

15. Newman RL, Connolly JF. Determining the role of phonology in silent reading using event-related brain potentials. Brain Res Cogn Brain Res 2004; 21:94-105.

16. Vissers CT, Chwilla DD, Kolk HH. Monitoring in language perception: The effect of misspellings of words in highly constrained sentences. Brain Res 2006; 1106: $150-163$.

17. Kutas M, Hillyard SA. Brain potentials reflect word expectancy and semantic association during reading. Nature 1984; 307: 161-163. 
18. Kramer AF, Donchin E. Brain potentials as indices of orthographic and phonological interaction during word matching. J Exp Psychol Learn Mem Cogn 1987; 13: 76-86.

19. Coltheart M. MRC Psycholinguistic Database. Q J Exp Psychol 1981; 33: 497505.

20. Courchesne E, Hillyard SA, Galambos R. Stimulus novelty, task relevance and the visual evoked potential in man. Electroencephalogr Clin Neurophysiol 1975; 39: 131-143.

21. Lukatela G, Turvey MT. Visual Lexical Access Is Initially Phonological: 1. Evidence From Associative Priming by Words, Homophones, and Pseudohomophones. J Exp Psychol Gen 1994; 123: 107-128.

22. Coltheart V, Patterson K, Leahy J. When a ROWS is a ROSE: Phonological effects in written word comprehension. Q J Exp Psychol 1994; 47: 917-955.

23. Briesemeister BB, Hofmann MJ, Tamm S, Kuchinke L, Braun M, Jacobs AM. The pseudohomophone effect: evidence for an orthography-phonology-conflict. Neurosci Lett 2009; 455:124-128.

24. Lazslo S, Federmeier KD. A beautiful day in the neighborhood: An eventrelated potential study of lexical relationships and prediction in context. J Mem Lang 2009; 61: 326-338.

25. Lambert BL, Lin S-J, Chang K-Y, Gandhi SK. Similarity As a Risk Factor in Drug-Name Confusion Errors: The Look-Alike (Orthographic) and Sound-Alike (Phonetic) Model. Med Care 1999; 37: 1214-1225. 
Fig. 1 a. Reaction times for correct trials (bars) and error rates (circles) in the 4 experimental conditions. b. Mean peak amplitude of the N2 and N400 in the 4 experimental conditions. BC: Best Completion, HO: Homophone, $\mathrm{PH}$ :

Pseudohomophone, UN: Unexpected Completion. Error bars depict the standard error of the mean in all cases. 
Fig. 2. ERP waves over the fronto-central region (linear derivation of electrodes FC1, FC2 and Fz) and centro-parietal region (linear derivation of electrodes $\mathrm{CP} 1, \mathrm{CP} 2$ and $\mathrm{Pz}$ ) averaged across the 15 participants. 


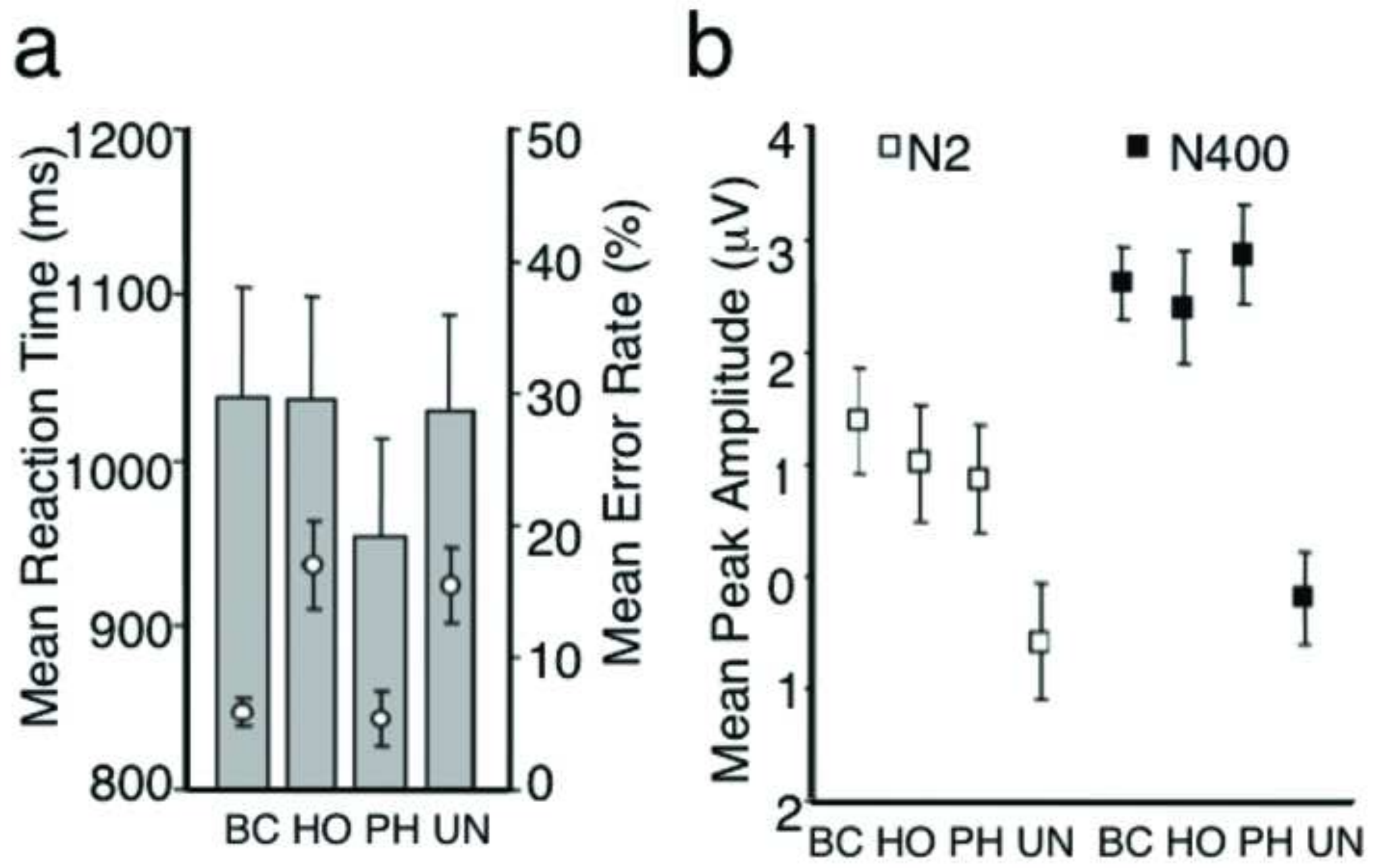



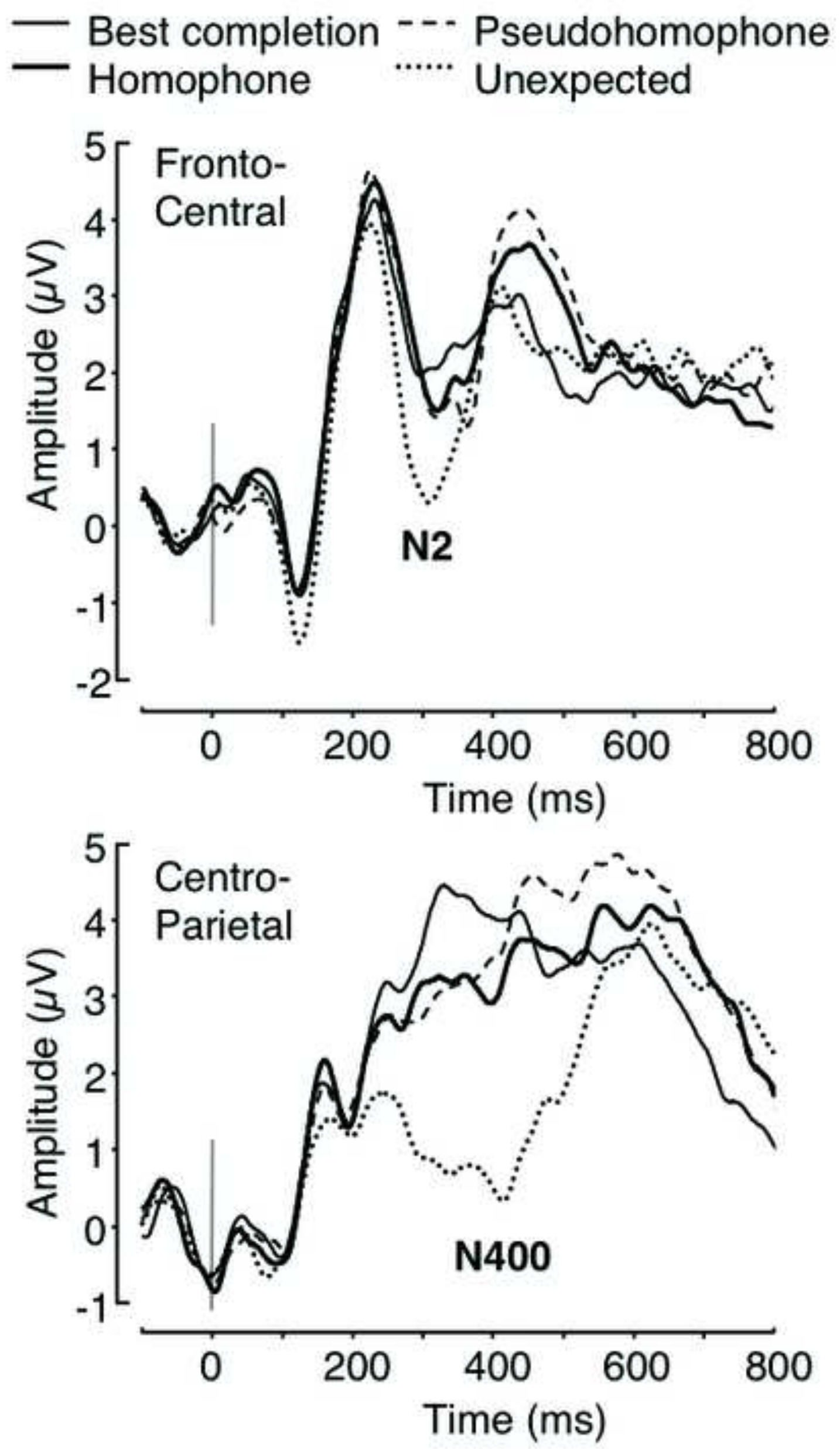